\title{
Designing a multifunctional artificial reef: studies on the influence of parameters with most influence in the vertical plane
}

\author{
José S. Antunes do Carmo • Maria G. Neves • \\ Mechteld ten Voorde
}

Received: 3 April 2010 /Revised: 20 August 2010 / Accepted: 20 August 2010 /Published online: 14 September 2010

(C) Springer Science+Business Media B.V. 2010

\begin{abstract}
Multifunctional artificial reefs are submerged breakwaters that serve several purposes. As well as protecting the local coastline, they enhance surfing possibilities and/or increase the environmental value of the area where they are situated. Multifunctional artificial reefs (MFARs) have some promising new aspects, too: first, they provide an unimpaired visual amenity, and second, they can offer tourist and economic benefits by improving the surfing conditions. Regarding the functionality of an MFAR, much research has been carried out on surfability, i.e. whether a wave is good for surfers. However, no research has yet been done on the influence of the submergence and the length of the reef slope on the breaker type, even though this is important for the design of the reef in terms of surfability. A preliminary design was achieved step by step, making use of the theory and state of the art of multifunctional artificial reefs (Voorde et al. 2009a, 2009b). This reef geometry was then used as an initial design in physical and numerical tests. These were performed to ascertain the capacity of a multifunctional reef to serve as a
\end{abstract}

J. S. Antunes do Carmo $(\bowtie) \cdot M$. ten Voorde

Department of Civil Engineering, IMAR-Institute of Marine

Research, University of Coimbra,

3030-788 Coimbra, Portugal

e-mail: jsacarmo@dec.uc.pt

M. ten Voorde

e-mail: mtvoorde@gmail.com

M. G. Neves $\cdot$ M. ten Voorde

NPE/DHA, National Civil Engineering Laboratory,

Av. do Brasil, no. 101,

1700-066 Lisbon, Portugal

M. G. Neves

e-mail: gneves@lnec.pt submerged breakwater and so protect the local coastline of Leirosa, Portugal, and improve the local surfing possibilities. This paper describes the numerical study conducted to analyze the influences of the main relevant parameters in the vertical plane, namely: the height, the submergence, and the length and slope of the reef. The investigation was conducted using the COBRAS-UC numerical model in the vertical plane and the main results and conclusions are described and presented; a brief discussion and some recommendations for future work are also included.

Keywords Multifunctional artificial reefs $\cdot$ Reef parameters $\cdot$ COBRAS-UC model $\cdot$ Numerical modeling . Parameters estimation

\section{Notations}

The following symbols are used in this paper:

COBRAS Cornell breaking waves and structures

COBRAS-UC Cornell breaking waves and structuresUniversity of Cantabria

COULWAVE Cornell University long and intermediate wave model

MFAR Multifunctional artificial reef

RANS Reynolds average Navier-Stokes equations; and

VOF Volume of fluid

\section{Introduction}

Various coastal structures can be used to solve, or at least to reduce, coastal erosion problems. Some of them, like breakwaters, seawalls and dikes, can provide direct protection while structures like detached breakwaters and artificial 


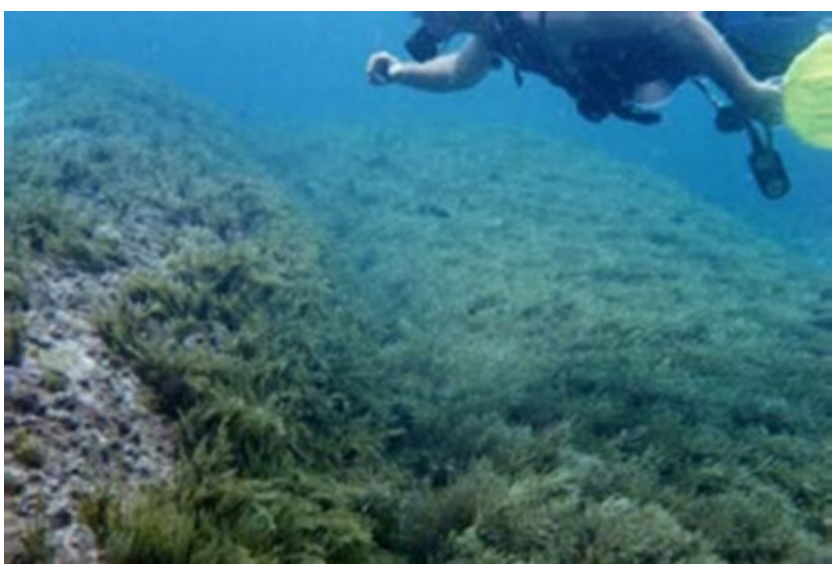

Fig. 1 Short algae and sea grasses on shallower containers of the Narrowneck reef (Jackson et al. 2004)

reefs provide indirect protection, reducing the hydraulic load on the coast to the level required to maintain the dynamic equilibrium of the shoreline. To achieve this objective, these structures are designed to allow the transmission of a certain amount of wave energy over the structure by overtopping (and also some transmission through the porous structure, in some types of breakwater), and/or wave breaking and the consequent energy dissipation on a shallow crest (submerged structures).

Rock walls, breakwaters or groynes usually serve the purpose of protecting land from erosion and/or enabling safe navigation into harbours and marinas, but other commercially valuable, multipurpose recreational and amenity enhancement objectives can also be incorporated into coastal protection and coastal development projects. Offshore breakwaters can be permanently submerged (reefs), permanently exposed or inter-tidal. In all cases the depth of the structure (submergence), its size and its position relative to the shoreline determine the coastal protection level provided by the structure. Submerged breakwaters may be an interesting and efficient solution since they would both protect a coastal system and improve the bathing conditions of some coastal zones. Therefore, these submerged structures, usually known as MultiFunctional Artificial Reefs (MFARs), represent an innovative concept for coastal protection. The functional design of these structures may still be insufficiently understood for optimum design but it may be just good enough for these structures to be considered as serious alternatives for coastal protection (Pilarczyk 2003). Additionally, with a proper design, waves can break over an MFAR in such a way that surfers can enjoy great sport riding them.

The construction of an MFAR can play a part in different kinds of coastal protection by:

- preventing coastal erosion

- increasing, in combination or not with sand nourishment, the stability of beaches.
These sorts of coastal protection are possible because an MFAR can:

- reduce the wave loads on the coast through a series of wave transformation processes that occur on the structure, viz., reflection and energy dissipation due to waves breaking on the structure and to flow circulation inside the porous media, which obviously depends on the construction material;

- create current circulation cells behind the reef, which can cause sedimentation at the shoreline (Henriquez 2004), and

- be used to regulate wave action, creating good surfable waves, by refraction and diffraction (Antunes do Carmo, Voorde and Neves, personal communication).

Multifunctional reefs are in fact an innovative measure for tackling coastal problems, and they have several advantages over both hard and soft measures.

The case studies show that traditional hard structures, like seawalls, revetment/slope protections, groynes and detached breakwaters, can work really well if the consequences are accepted. If erosion is predicted for and accepted elsewhere, the overall performance can be good.

Soft measures, like beach and dune nourishment, submerged nourishment, vegetation techniques and cliff stabilization can be a short term solution. Erosion can continue at the same rate and soon the action (measure) needs to be repeated. This is especially true in the Atlantic coast where wave heights and tidal amplitudes can be quite large.

Due to their particularity of 'working with nature', soft solutions are found to be effective only in a medium to long-term perspective, i.e. when coastal erosion does not constitute a risk in the short-term (5-10 years). Their impacts do indeed slow down coastline retreat, but they don't stop it. The long term positive effect of soft solutions may be optimized by hard structures which make it possible to tackle an erosion problem efficiently but have a limited lifetime (in general no more than 10 years).

Some innovative measures have been implemented in the last few years. Among them, we can refer to: beach drainage systems, deposition of volcanic gravels to retain sand on which plants germinate, beginning the process of soil regeneration and dune formation, construction of protective barriers of dunes, using geotextile sand containers, and submerged structures including artificial reefs.

Table 1 Parameter values of the geometry

\begin{tabular}{lcccc}
\hline $\mathrm{h} \_$reef $(\mathrm{m})$ & $\tan \alpha$ & $\tan \beta$ & $\mathrm{L}_{\mathrm{s}}(\mathrm{m})$ & $\mathrm{L}_{\mathrm{b}}(\mathrm{m})$ \\
\hline 0.190 & $1: 10$ & $1: 50$ & 1.90 & 7.50 \\
0.360 & & & & \\
\hline
\end{tabular}




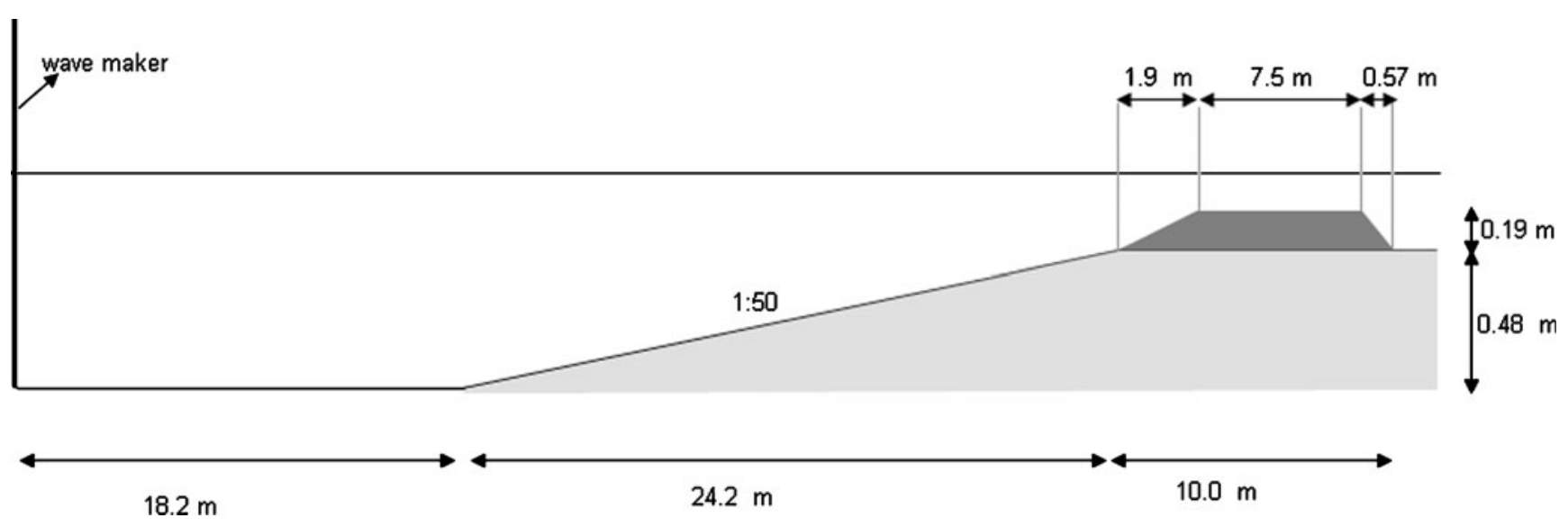

Fig. 2 Schematic representation of the tested geometry

The most suitable construction material for multifunctional artificial reefs is geotextile, used as geocontainer and/ or geotube systems. Geotextiles are a family of synthetic materials that include polyethylene, polyester and polypropylene. In their most usual form they are flexible, permeable and durable fabric sheets that are resistant to tension and tearing. They can be sewn or ultra-sonically welded to produce containers designed to retain sand or mortar for use as a construction material. Geotextile containers can be filled and placed using many different methods depending on the site location, the available bottom, the container size and shape, the filling material, and the type of geotextile fabric chosen.

Table 2 Test conditions

\begin{tabular}{llll}
\hline$H(\mathrm{~m})$ & $S(\mathrm{~m})$ & $h(\mathrm{~m})$ & $T(\mathrm{~s})$ \\
\hline 0.10 & 0.08 & 0.75 & \\
& 0.12 & 0.79 & \\
0.15 & 0.08 & 0.75 & \\
& 0.12 & 0.79 & \\
& 0.16 & 0.83 & 2.52 \\
& 0.20 & 0.87 & 2.84 \\
0.20 & 0.12 & 0.79 & 3.16 \\
& 0.16 & 0.83 & \\
& 0.20 & 0.87 & \\
0.25 & 0.24 & 0.91 & \\
& 0.16 & 0.83 & \\
0.30 & 0.20 & 0.87 & \\
& 0.24 & 0.91 & \\
0.35 & 0.20 & 0.87 & \\
& 0.24 & 0.91 & \\
& 0.24 & 0.91 &
\end{tabular}

$H$ wave height, $S$ submergence, $h$ water depth, $T$ period
Sand-filled geotextile containers are becoming increasingly recognized as a tool for coastal defence. Marine ecosystem enhancement is another relevant advantage of the use of geotextile sand containers. These containers have appeared to provide an excellent substrate for marine flora and the development of a diverse ecosystem (Jackson et al. 2004). As an example, Fig. 1 shows a detail of short algae and sea grasses on shallower containers of the Narrowneck artificial reef constructed in 2000 at the Gold Coast of Australia.

When the ecosystem on the Narrowneck reef was well developed, a clear zoning between areas of sea grass and kelp could be observed. Visually, the macroalgal communities dominated the reef, covering over $70 \%$ of the reef surface. It was also populated by a variety of other benthos, including coralline algae, submassive sponges, ascidians, octocorals (soft corals), hydroids and crinoids (feather starfish), echinoids (sea urchin) and abalone. Observations by the National Marine Science Centre indicated that "the biological communities associated with Narrowneck Artificial Reef appear to enhance biodiversity and productivity at a local scale and may also contribute to overall regional productivity" (Edwards 2003).

Several reasons may account for the growing interest of MFARs, using geotextile material, over conventional ways of protecting a local coastline:

- these structures have, by definition, a minimal visual intrusion that especially enhances their value in zones with strong aesthetic constraints;

- the water renewal induced by the high level of transmission is desirable to avoid stagnation and ensure satisfactory quality for recreational waters, especially in tideless seas, and water oxygenation for animals and plants living in the protected area leeward of the breakwater; 

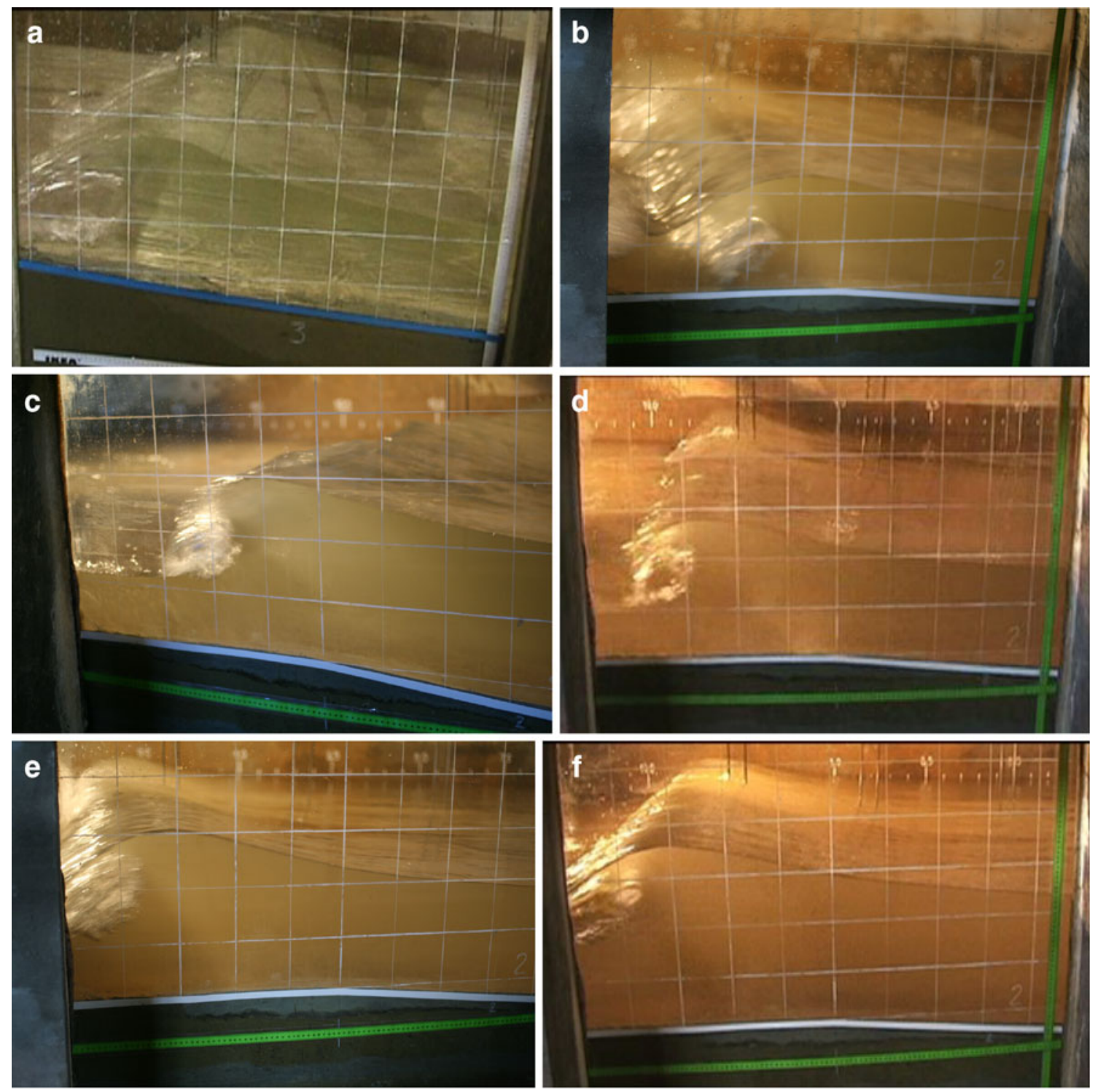

Fig. 3 Breaker type for two heights of the reef $(0.19 \mathrm{~m}, 0.36 \mathrm{~m})$, three submergences $(0.12 \mathrm{~m}, 0.16 \mathrm{~m}, 0.20 \mathrm{~m})$, a single input wave height $(0.15 \mathrm{~m})$ and three periods $(2.52 \mathrm{~s}, 2.84 \mathrm{~s}, 3.16 \mathrm{~s})$. a Breaker type for: h_reef $=0.36 \mathrm{~m}, S=0.12 \mathrm{~m}, H=0.15 \mathrm{~m}, T=2.84 \mathrm{~s}$. b Breaker type for: h_reef $=0.19 \mathrm{~m}, S=0.12 \mathrm{~m}, H=0.14 \mathrm{~m}, T=3.16 \mathrm{~s}$. c Breaker type for:

h_reef $=0.19 \mathrm{~m}, S=0.16 \mathrm{~m}, H=0.14 \mathrm{~m}, T=2.84 \mathrm{~s}$. d Breaker type for: h_reef $=0.19 \mathrm{~m}, S=0.16 \mathrm{~m}, H=0.14 \mathrm{~m}, T=2.52 \mathrm{~s}$. e Breaker type for: h_reef $=0.19 \mathrm{~m}, S=0.20 \mathrm{~m}, H=0.15 \mathrm{~m}, T=2.52 \mathrm{~s}$. f Breaker type for: h_reef $=0.36 \mathrm{~m}, S=0.20 \mathrm{~m}, H=0.15 \mathrm{~m}, T=2.52 \mathrm{~s}$

- the structure is interesting in economic terms. First, geotextile sand containers tend to be cheaper per unit volume than rubble-mound structures, and second, the surfing aspect can attract the tourism, which is good for the local economy;

- the geotextile sand containers have proved to be stable even for the 8-10 m amplitude waves that occur in the Atlantic coast during some winter storms;

- the expansion of the environmental value is a great benefit in the present times, in which nature is being destroyed more and more, by the behavior of humans.

Design steps of a preliminary MFAR are presented in Voorde et al. (2008, 2009a, 2009b). Taking this preliminary design, physical and numerical tests were performed to investigate whether an MFAR could protect a specific local coastline and enhance the surfing possibilities.

The main purpose of this paper is to show results of a numerical model and to present some preliminary conclusions in relation to the optimal geometry for the MFAR, which is designed with two main aims: (1) to protect a sand dune system on the Portuguese coast, and (2) to generate good waves for surfing. 
Fig. 4 Relevant reef parameters to be investigated. a Height ( $h$ reef) and submergence (S) of the reef. b Reef angle $(\theta)$, slope of the structure (S_reef), distance shoreline-apex reef, and horizontal dimensions.

c Geometry of the reef (without and with platform)

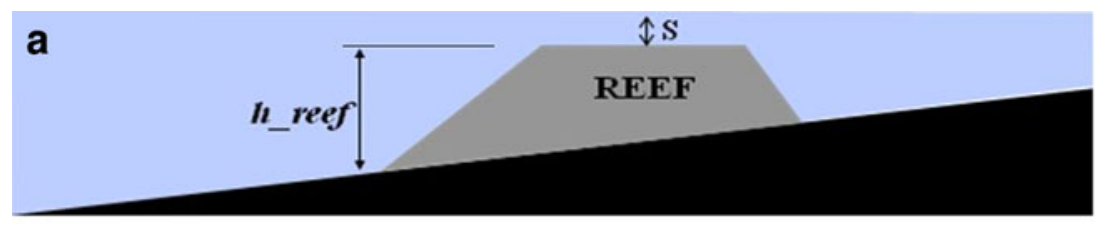

b

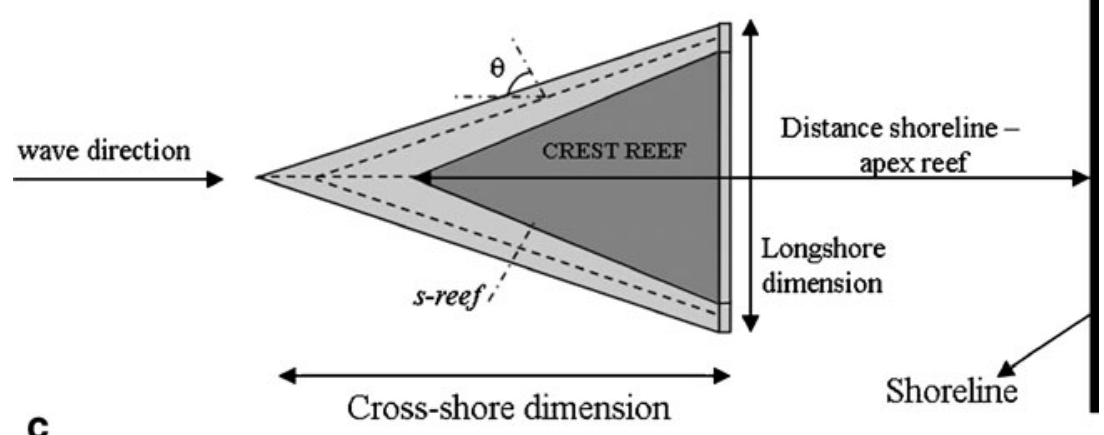

With platform
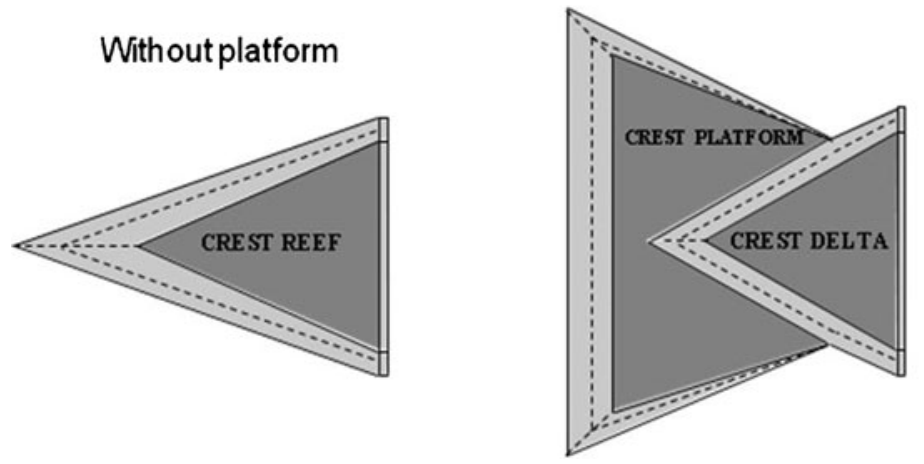

\section{Physical tests}

A physical study conducted in LNEC-Portugal is presented in Voorde (2009) and Voorde et al. (2009c). The 2D flume used in this study is $73.0 \mathrm{~m}$ long, $3.0 \mathrm{~m}$ wide and $2.0 \mathrm{~m}$ deep. The model was operated according to Froude's similarity law; the geometrical scale was 1:10. Table 1 shows the parameter values of the geometry, which is shown in Fig. 2, and Table 2 shows the test conditions (Voorde et al. 2009c).

Fifty-one tests were run: 17 combinations of varying wave heights and varying submergences were tested. Each wave height was tested with three different periods.
Figure 3 shows the physical results of the breaker type for two heights of the reef (h_reef $=0.19 \mathrm{~m}$ and $0.36 \mathrm{~m}$ ), three submergences $(S=0.12 \mathrm{~m}, 0.16 \mathrm{~m}$ and $0.20 \mathrm{~m})$, a single input wave height $(H=0.15 \mathrm{~m})$ and three periods $(T=2.52 \mathrm{~s}, 2.84 \mathrm{~s}$ and $3.16 \mathrm{~s})$. The title of each test gives the measured wave height and period at a distance of $5.10 \mathrm{~m}$ from the wave maker. The wave height in all tests was smaller than the input value, by reason of some energy lost.

The physical study has shown that the breaking wave shape gets better when the submergence $(\mathrm{S})$ is larger than $0.12 \mathrm{~m}$ and when the wave height $(\mathrm{H})$ is larger than $0.10 \mathrm{~m}$; this physical study also showed that a submer-

Fig. 5 Height of the reef: tested geometry

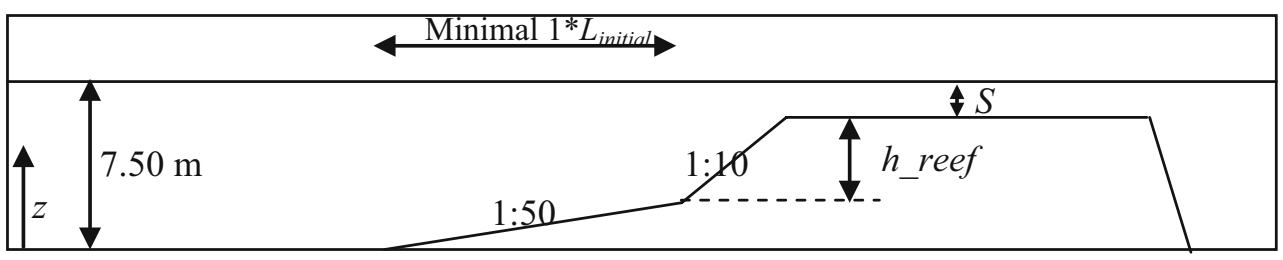


Table 3 Height of the reef: geometry parameters and wave conditions

\begin{tabular}{llccc}
\hline$h$ reef $(\mathrm{m})$ & s_reef $(\mathrm{m})$ & $S(\mathrm{~m})$ & $H(\mathrm{~m})$ & $T(\mathrm{~s})$ \\
\hline 1.90 & $1: 10$ & 1.50 & 1.50 & 9.0 \\
3.90 & & & & \\
3.20 & & & & \\
\hline
\end{tabular}

gence of $1.60 \mathrm{~m}$ (prototype scale) in most cases still gives a good breaking wave for the design wave height of $1.50 \mathrm{~m}$.

\section{Numerical model-COBRAS-UC}

To confirm these results and gain a better insight into the influence of the breaker type and into the position of the breaking waves, numerical simulations with COBRAS-UC (Garcia et al. 2004) were made for several heights, several submergences and several slopes of the reef. This research on the height, the submergence and the slope of the reef with the COBRAS-UC model is presented in section "Numerical simulations".

The numerical simulations were performed on a prototype scale for three different wave heights. Several slopes were also tested with COBRAS-UC, to confirm the slope of $1: 10$. The design wave is $1.50 \mathrm{~m}$ height and has a $9 \mathrm{~s}$ period. These conditions have provided the input values for a geometry that was also tested in $2 \mathrm{DH}$ numerical simulations using the Boussinesq-type COULWAVE model (Voorde 2009).
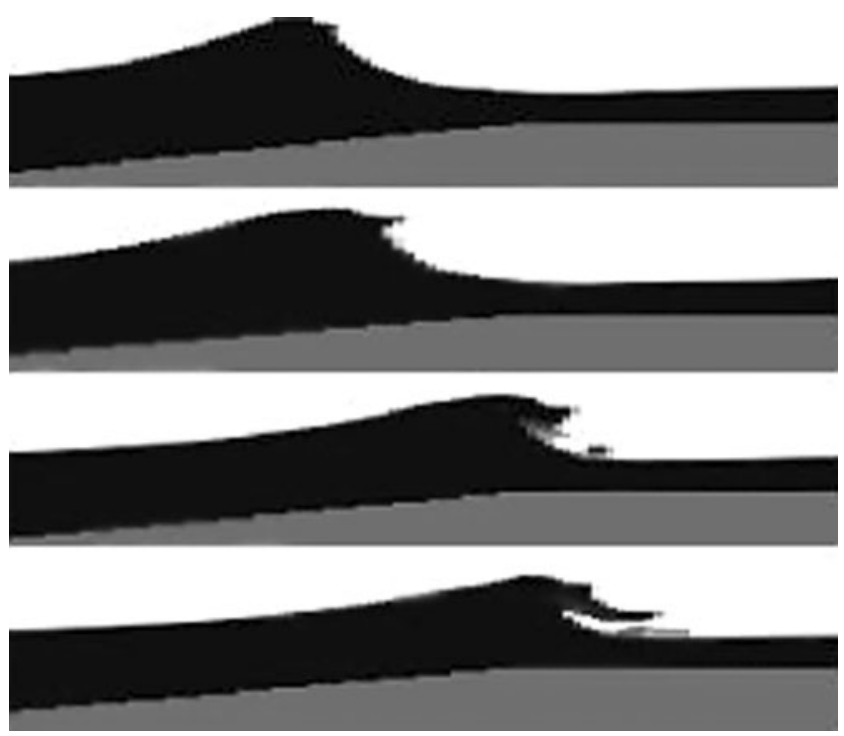

Fig. 6 Wave shape on the reef $1.90 \mathrm{~m}$ high (h_init $=7.50 \mathrm{~m}, S=1.50 \mathrm{~m}$, $H=1.50 \mathrm{~m}, T=9.0 \mathrm{~s}$ )
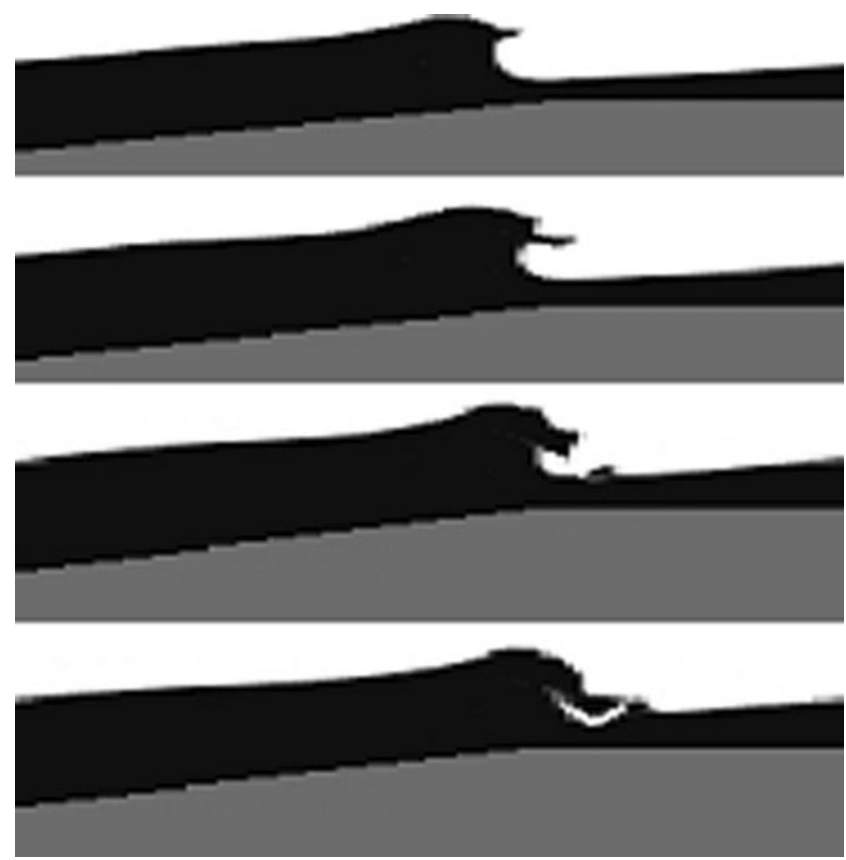

Fig. 7 Wave shape on the reef $3.90 \mathrm{~m}$ high (h init $=7.50 \mathrm{~m}, S=1.50 \mathrm{~m}$, $H=1.50 \mathrm{~m}, T=9.0 \mathrm{~s}$ )

By taking the Reynolds Average Navier-Stokes (RANS) equations, Liu et al. (1999) presented a two-dimensional (in the vertical plane) numerical model COBRAS (COBRAS = Cornell Breaking Waves and Structures) to describe the flow inside and outside coastal structures. Hsu et al. (2002) extended the preliminary model by including a set of volume-averaged $k-\varepsilon$ turbulence balance equations.

The COBRAS model solves the 2DV RANS Eqs. 1 and 2, based on the decomposition of the instantaneous
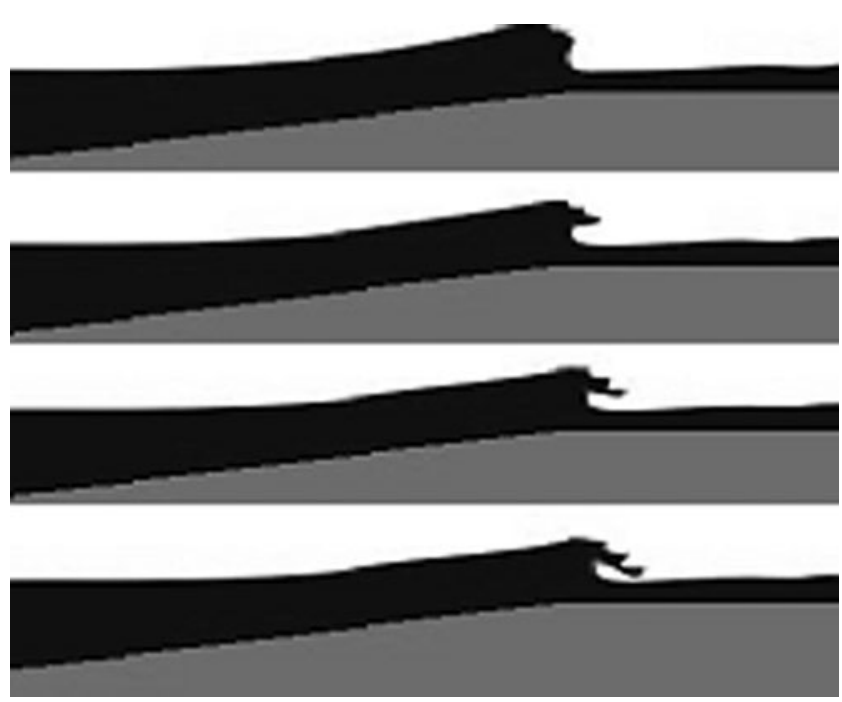

Fig. 8 Wave shape on the reef $3.20 \mathrm{~m}$ high (h_init $=7.50 \mathrm{~m}, S=1.50 \mathrm{~m}$, $H=1.50 \mathrm{~m}, T=9.0 \mathrm{~s})$ 
Fig. 9 Height of the reef: wave height development on the reef

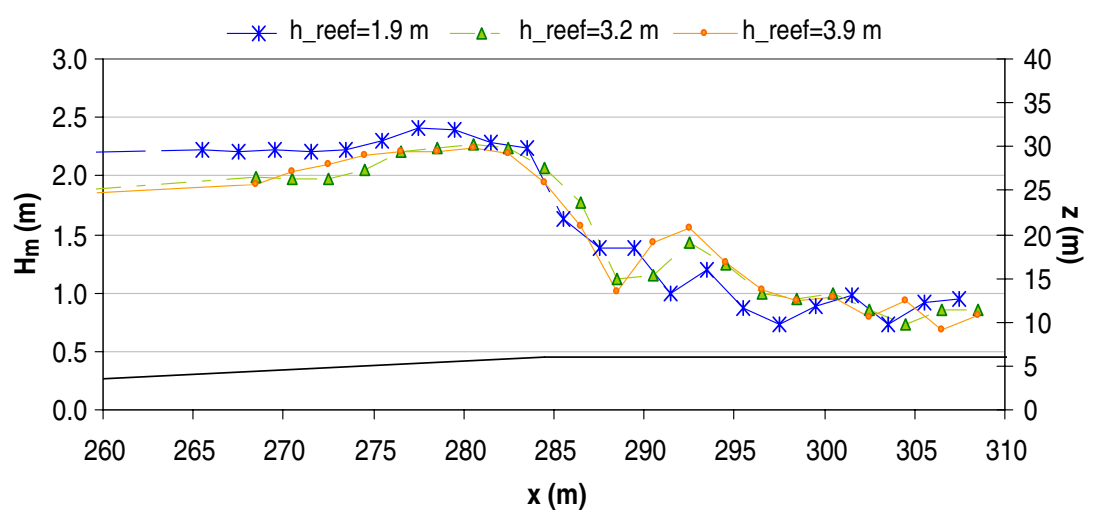

velocity, $u$, and pressure field, $p$, into mean $\langle$.$\rangle and$ turbulent components (.'):

$\frac{\partial\left\langle u_{i}\right\rangle}{\partial x_{i}}=0$

$$
\begin{aligned}
\frac{\partial\left\langle u_{i}\right\rangle}{\partial t} & +\left\langle u_{j}\right\rangle \frac{\partial\left\langle u_{i}\right\rangle}{\partial x_{j}}=-\frac{1}{\rho} \frac{\partial\langle p\rangle}{\partial x_{i}}+g_{i}+\frac{1}{\rho} \frac{\partial\left\langle\tau_{i j}\right\rangle}{\partial x_{j}} \\
& -\frac{\partial\left\langle u_{i}^{\prime} u_{j}^{\prime}\right\rangle}{\partial x_{j}}
\end{aligned}
$$

and the $k-\varepsilon$ Eqs. 3 and 4 for the turbulent kinetic energy $(k)$, and the turbulent dissipation rate $(\varepsilon)$ :

$$
\begin{aligned}
& \frac{\partial k}{\partial t}+\left\langle u_{j}\right\rangle \frac{\partial k}{\partial x_{j}}=-\frac{\partial}{\partial x_{j}}\left[\left(\frac{v_{t}}{\sigma_{k}}+v\right) \frac{\partial k}{\partial x_{j}}\right] \\
&-\left\langle u_{i}^{\prime} u_{j}^{\prime}\right\rangle \frac{\partial\left\langle u_{i}\right\rangle}{\partial x_{j}}-\varepsilon \\
& \frac{\partial \varepsilon}{\partial t}+\left\langle u_{j}\right\rangle \frac{\partial \varepsilon}{\partial x_{j}}=\frac{\partial}{\partial x_{j}}\left[\left(\frac{v_{t}}{\sigma_{\varepsilon}}+v\right) \frac{\partial \varepsilon}{\partial x_{j}}\right] \\
&+2 C_{1 \varepsilon} \frac{\varepsilon}{k} v_{t} S_{i j} \frac{\partial\left\langle u_{j}\right\rangle}{\partial x_{i}}-C_{2 \varepsilon} \frac{\varepsilon^{2}}{k}
\end{aligned}
$$

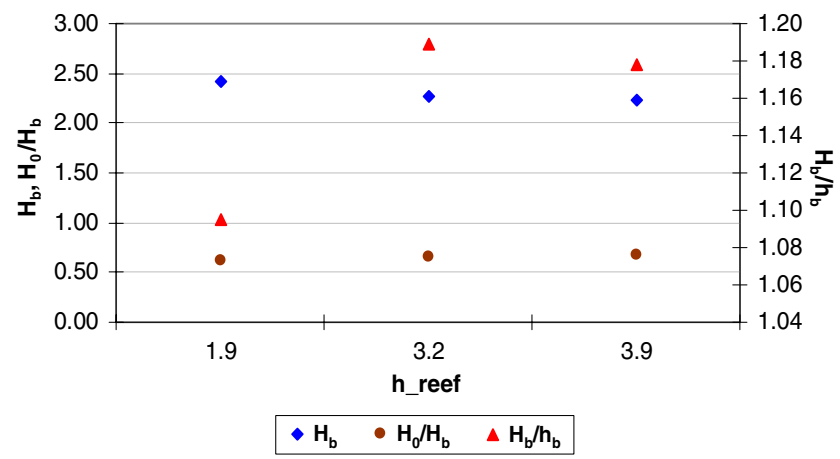

Fig. 10 Influence of $h \_$reef on the $H_{b}, H_{0} / H_{b}$ and $H_{b} / h_{b}$ values where $i, j=1,2$ for a two-dimensional flow, $\rho$ is the density of fluid, $g_{i}$ is the $i$ th component of the gravitational acceleration, $\left\langle\tau_{i j}\right\rangle$ is the viscous stress tensor of the mean flow and $\nu_{t}=C_{d} k^{2} / \varepsilon$ is the eddy viscosity, in which $C_{d}$ is a coefficient depending on the local strain rate. For a Newtonian fluid $\left\langle\tau_{i j}\right\rangle=2 \mu\left\langle S_{i j}\right\rangle$, with $\mu=\nu \rho$ being the molecular viscosity and $\left\langle S_{i j}\right\rangle=1 / 2\left(\partial\left\langle u_{i}\right\rangle / \partial x_{j}+\right.$ $\left.\partial\left\langle u_{j}\right\rangle / \partial x_{i}\right)$, the rate of strain tensor of the mean flow.

The influence of turbulence fluctuations on the mean flow field is represented by the Reynolds stresses $\rho\left(u_{i}^{\prime} u_{j}^{\prime}\right)$. The governing equations for $k-\varepsilon$ are derived from the Navier-Stokes equations, and higher order correlations of turbulence fluctuations in $k$ and $\varepsilon$ equations are replaced by closure conditions. The empirical coefficients $\left(C_{1 \varepsilon}=1.44\right.$, $C_{2 \varepsilon}=1.92, \sigma_{\varepsilon}=1.3$ and $\left.\sigma_{k}=1.0\right)$ were experimentally determined from stationary flows (Rodi 1980).

A nonlinear Reynolds stress model is employed to relate the Reynolds stresses and the strain rates of the mean flowEq. 5:

$$
\begin{aligned}
\left\langle u_{i}^{\prime} u_{j}^{\prime}\right\rangle=\frac{2}{3} k \delta_{i j} & -C_{d} \frac{k^{2}}{\varepsilon}\left(\frac{\partial\left\langle u_{i}\right\rangle}{\partial x_{j}}+\frac{\partial\left\langle u_{j}\right\rangle}{\partial x_{i}}\right) \\
-\frac{k^{3}}{\varepsilon^{2}} & {\left[C_{1}\left(\frac{\partial\left\langle u_{i}\right\rangle}{\partial x_{l}} \frac{\partial\left\langle u_{l}\right\rangle}{\partial x_{j}}+\frac{\partial\left\langle u_{j}\right\rangle}{\partial x_{l}} \frac{\partial\left\langle u_{l}\right\rangle}{\partial x_{i}}-\frac{2}{3} \frac{\partial\left\langle u_{l}\right\rangle}{\partial x_{k}} \frac{\partial\left\langle u_{k}\right\rangle}{\partial x_{l}} \delta_{i j}\right)\right.} \\
& +C_{2}\left(\frac{\partial\left\langle u_{i}\right\rangle}{\partial x_{k}} \frac{\partial\left\langle u_{j}\right\rangle}{\partial x_{k}}-\frac{1}{3} \frac{\partial\left\langle u_{l}\right\rangle}{\partial x_{k}} \frac{\partial\left\langle u_{l}\right\rangle}{\partial x_{k}} \delta_{i j}\right) \\
& \left.+C_{3}\left(\frac{\partial\left\langle u_{k}\right\rangle}{\partial x_{i}} \frac{\partial\left\langle u_{k}\right\rangle}{\partial x_{j}}-\frac{1}{3} \frac{\partial\left\langle u_{l}\right\rangle}{\partial x_{k}} \frac{\partial\left\langle u_{l}\right\rangle}{\partial x_{k}} \delta_{i j}\right)\right]
\end{aligned}
$$

where $\delta_{i j}$ is the Kronecker delta, $C_{d}=(2 / 3)\left[1 /\left(7.4+S_{\max }\right)\right]$, $C_{1}=1 /\left(185.2+D_{\max }^{2}\right), C_{2}=1 /\left(58.5+D_{\max }^{2}\right)$ and $C_{3}=$ $1 /\left(370.4+D_{\max }^{2}\right)$, where $S_{\max }=(\langle k\rangle /\langle\varepsilon\rangle) \max \left|\partial\left\langle u_{i}\right\rangle / \partial x_{i}\right|$ and $D_{\max }=(\langle k\rangle /\langle\varepsilon\rangle) \max \left|\partial\left\langle u_{i}\right\rangle / \partial x_{j}\right|$ (see Rodi 1980; Lin and Liu 1998; Hsu et al. 2002, for details). The movement of the free surface is tracked by the volume-of-fluid (VOF) method.

COBRAS-UC is a new version of the model developed at the University of Cantabria in order to overcome some of the initial limitations and especially to convert it into a tool for practical application. Most of these modifications in the new version of COBRAS-UC are based on the extensive valida- 
Fig. 11 Slope of the reef: tested geometry

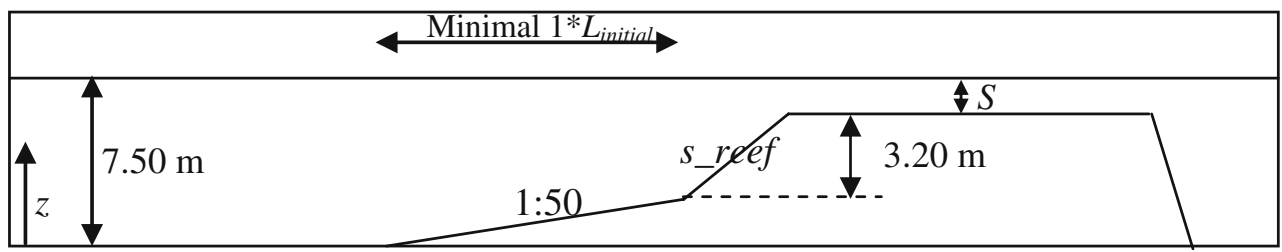

tion work carried out for low-crested structures (Garcia et al. 2004; Losada et al. 2005; Lara et al. 2006a) and for wave breaking on permeable slopes (Lara et al. 2006b).

The improvements cover the wave generation process; code updating and refactoring; optimization and improvement of the main subroutines; improvement of input and output data definition and the development of a graphical user interface and output data processing programs (Losada et al. 2008). In that study, the COBRAS-UC model was used to calculate the mean wave overtopping discharge for an emerged breakwater, which is basically a combination of an impermeable concrete vertical wall with a two-layer permeable rock slope in front of it.

A more recent application of the COBRAS-UC model to wave overtopping analysis is presented in Lara et al. (2008). This paper also presents some comparisons between results of low-mound and rubble-mound breakwaters.

\section{Reef parameters}

Several design parameters have to be considered for the design of any artificial reef that is to be built to both protect the local coastline and to create surfing conditions. The factors that should be taken into account for these parameters in terms of hydrodynamics are described below. We concentrate our study on hydrodynamics, but it should be pointed out that once an optimal geometry has been established for the hydrodynamics a thorough morphodynamic study (physical and/or numerical) is necessary to ascertain the capacity of the MFAR to protect a local coastline. A numerical study on the shoreline response to an imaginary (V-shaped) multifunctional submerged structure is presented in Ranasinghe et al. (2006). That study identifies the main nearshore processes that govern the mode of shoreline response (i.e., erosive vs. accretive) and examines the impact of three important parameters that

Table 4 Slope of the reef: geometry parameters and wave conditions

\begin{tabular}{lllll}
\hline s_reef & h_reef $(\mathrm{m})$ & $S(\mathrm{~m})$ & $H(\mathrm{~m})$ & $T(\mathrm{~s})$ \\
\hline $1: 06$ & 3.20 & 1.50 & 1.50 & 9.0 \\
$1: 10$ & & & & \\
$1: 14$ & & & & \\
$1: 18$ & & & & \\
\hline
\end{tabular}

govern the mode and magnitude of the shoreline response to a V-shaped submerged structure.

Figure 4 below shows the more relevant parameters to be investigated, namely: a) the reef height and the reef submergence, b) the reef angle, the slope of the reef structure, the distance of the shoreline to the apex structure and the horizontal dimensions, and c) the reef geometry (without and with platform).

The height of the reef depends on its submergence, its slopes, its horizontal dimensions and its distance from the shore. However, the height needs a minimum value in relation to the breaker type.

The submergence of the reef is determined by two factors. First, it should be shallow enough for the design waves to break on the reef. Second, it should be deep enough to ensure the safety of surfers. It depends on the design breaking wave height and on the breaking condition; in principle, a value no greater than the offshore wave height is necessary to get a surfable wave for a reef slope of $1: 10$.

Assuming a breaker criterion of $H_{b}=\gamma_{b} h_{b}$, with $\gamma_{b}=$ $1.20 \xi_{b}{ }^{0.27}$ (Kaminsky and Kraus, 1993), which gives for a reef slope of $1: 10$ a critical breaking condition $H_{b}=1.30 h_{b}$ for the smallest breaking depth, the submergence $S$ of the reef with, for example, a $2.0 \mathrm{~m}$ design breaking wave height is $1.50 \mathrm{~m}$. Another important consideration, for reasons of safety, is that the submergence should be of the

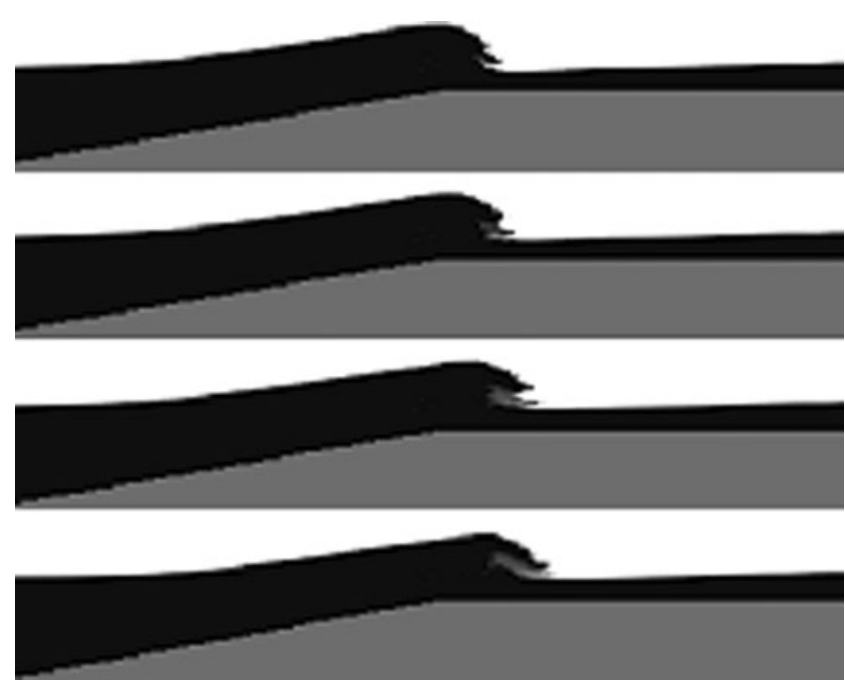

Fig. 12 Wave shape on the reef with a slope of 1:06 (h init $=7.50 \mathrm{~m}$, h_reef $=3.20 \mathrm{~m}, S=1.50 \mathrm{~m} ; H=1.50 \mathrm{~m}, T=9.0 \mathrm{~s}$ ) 

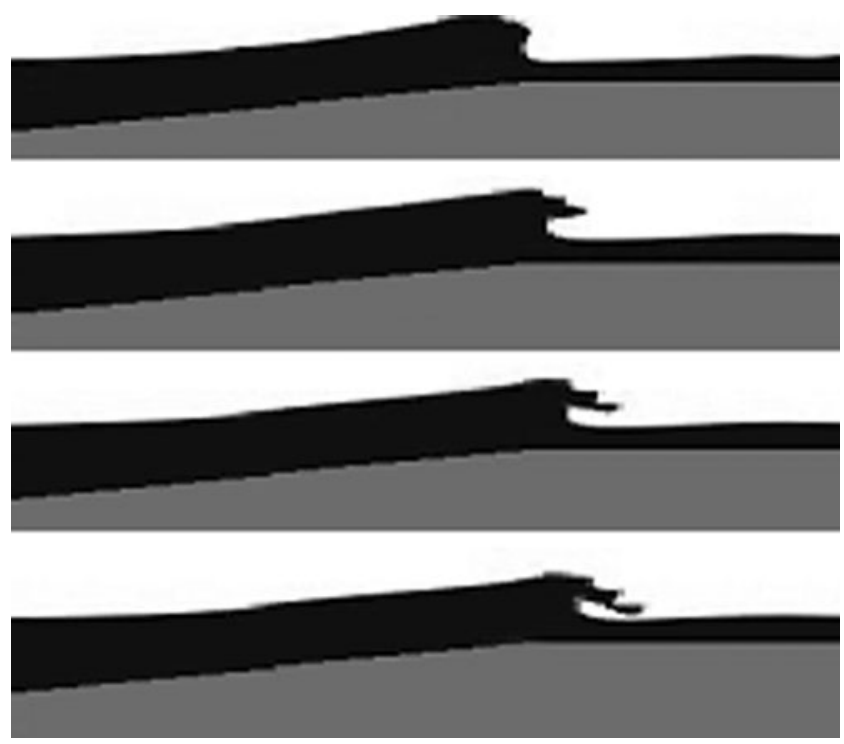

Fig. 13 Wave shape on the reef with a slope of 1:10 (h_init $=7.50 \mathrm{~m}$, h_reef=3.20 m, $S=1.50 \mathrm{~m} ; H=1.50 \mathrm{~m}, T=9.0 \mathrm{~s}$ )

same order of magnitude of the design wave height in deep water.

For reasons of safety, it should be noted that both the design wave height and the corresponding design submergence mentioned above should be for low tide, because this tidal level gives the critical submergence. However, for reasons of coastal protection, it must be noted that the reef structure will be more efficient with a submergence of about $0.30-0.50 \mathrm{~m}$ for the minimum tidal level.

For a certain reef slope, the height determines the length of the reef's side. This should be long enough for the wave to feel the reef and also to break in accordance with the bottom slope.
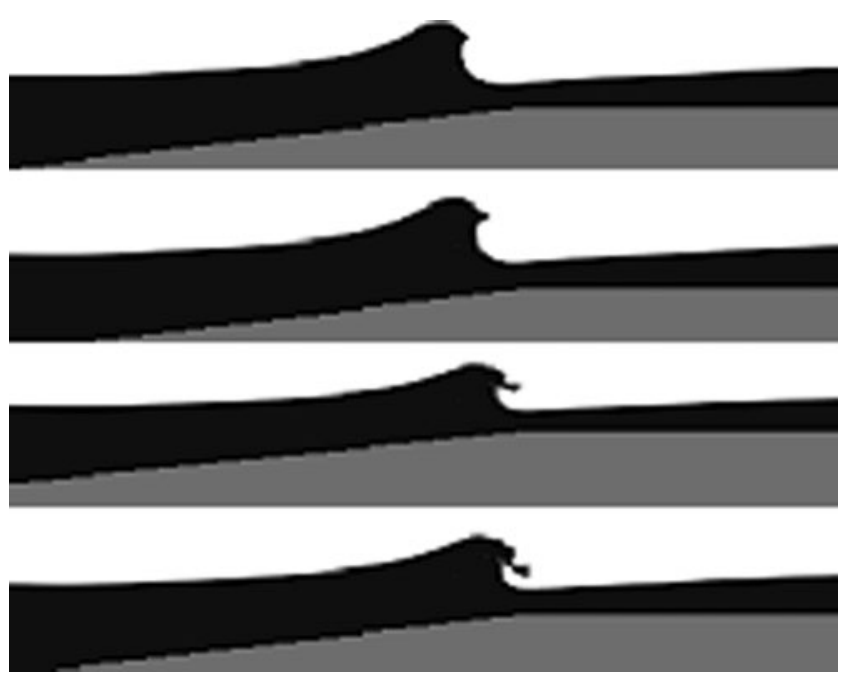

Fig. 14 Wave shape on the reef with a slope of 1:14 (h_init=7.50 m, h_reef $=3.20 \mathrm{~m}, S=1.50 \mathrm{~m} ; H=1.50 \mathrm{~m}, T=9.0 \mathrm{~s}$ )
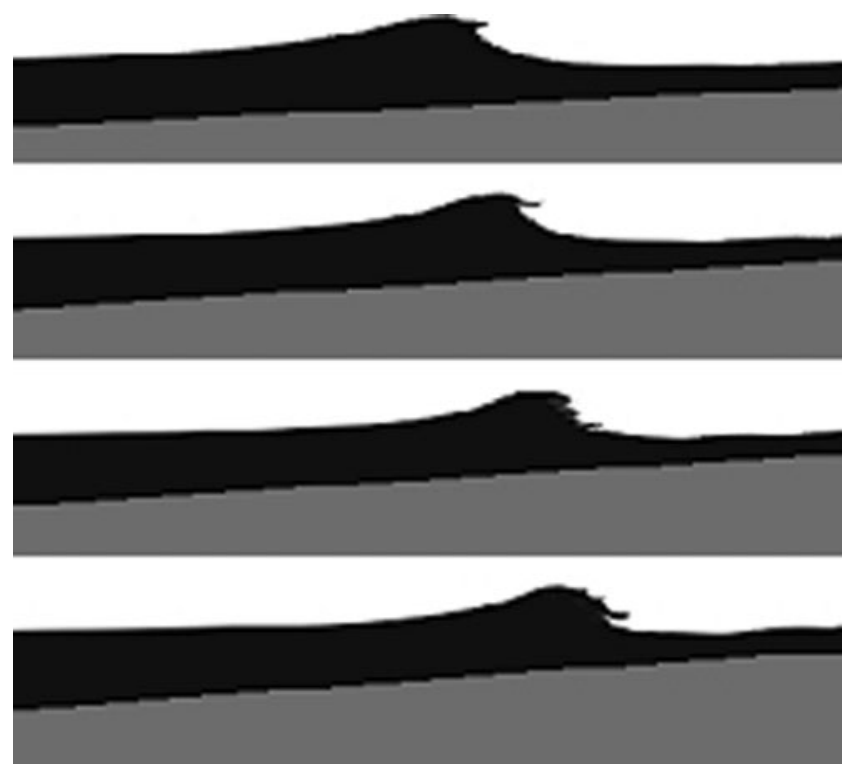

Fig. 15 Wave shape on the reef with a slope of 1:18 (h_init $=7.50 \mathrm{~m}$, h_reef $=3.20 \mathrm{~m}, S=1.50 \mathrm{~m} ; H=1.50 \mathrm{~m}, T=9.0 \mathrm{~s}$ )

The shape of a breaking wave is of great importance for surfing. The categorization of the different breaker type regimes is described by the well-known inshore Iribarren number.

Numerical simulations should be performed to determine the exact length required for the reef side, for the proper breaker type, as a function of the wave length, and thus the reef height.

The horizontal alongshore dimension depends on the length of the local coastline to be protected. A predictive empirical relationship is proposed as a preliminary engineering tool to assess the shoreline response to submerged structures. This relationship is $S_{a} / S Z W>1.5$, where $S_{a}$ is the distance from the apex of the structure to the undisturbed shoreline and $S Z W$ is the natural surf zone width.

\section{Numerical simulations}

The height of the reef

The height of the reef is the first parameter to be investigated because the first thing that has to be known is the length of the reef. This is in order to guarantee that it is long enough to get the desired breaker type. Two reef heights, $h \_$reef (Fig. 5 and Table 3) were tested at first (Voorde 2009):

- h_reef $=1.90 \mathrm{~m}$, as in the physical experiments;

- hreef $=3.90 \mathrm{~m}$, about twice as high as in the physical experiments in order to have a broader range of heights $(2 \mathrm{~m})$. 
Fig. 16 Slope of the reef: wave height development on the reef
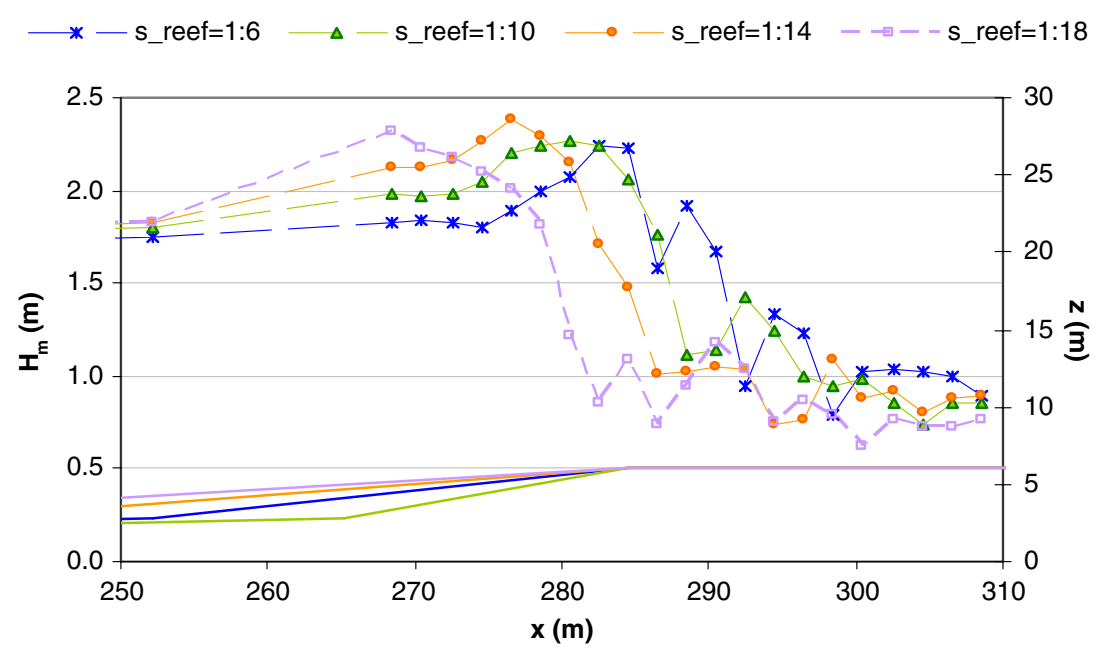

As mentioned above, the submergence is $1.50 \mathrm{~m}$ and the slope chosen for the reef is 1:10. Figure 5 shows the geometry tested and Table 3 presents the geometry parameters and the wave conditions. $L_{\text {initial }}$ is the wavelength at the source.

Figures 6 and 7 (Voorde et al. 2009c) show that with a $1.90 \mathrm{~m} \mathrm{~h}$ reef a spilling break is formed, and with a reef height of $3.90 \mathrm{~m}$ a plunging break is formed. Figure 6 is to be compared with Fig. 3c), since it shows a sequence of numerical results for the same experimental conditions of the latter figure. Since a plunging break is preferred for surfing, a third simulation was conducted to see if a plunging break can be achieved with a lower height, i.e., $3.20 \mathrm{~m}$. The results of the breaker shape are shown in Fig. 8. This Figure shows that a plunging break is still formed when the reef is $3.20 \mathrm{~m}$ high. A height of $3.20 \mathrm{~m}$ means a length of $32 \mathrm{~m}$ for the reef; this value is about half the wavelength at the start of the reef, $L_{\text {start_reef }}(59 \mathrm{~m})$. So a reef length of $0.5 \times L_{\text {start_reef }}$ is assumed to be the minimum needed to form a surfable wave.

Figure 9 shows the calculated wave height, $H_{m}$, at several points on the reef for all three tested reef heights,

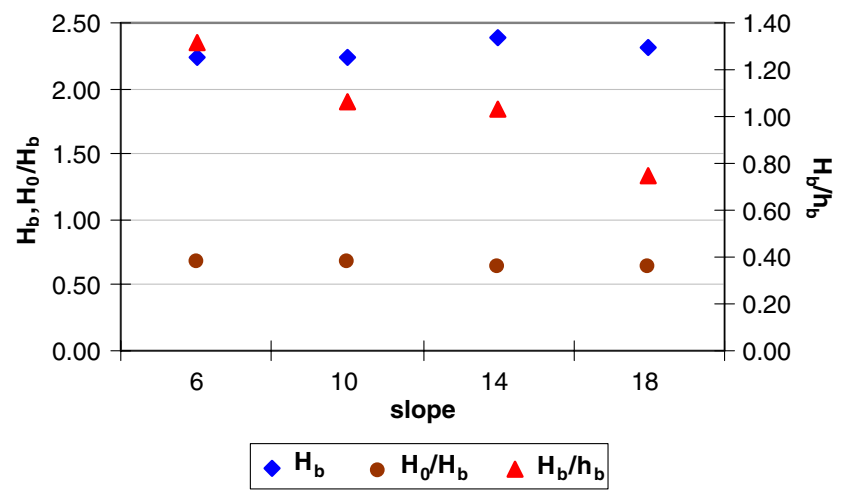

Fig. 17 Influence of $s_{-}$reef on the $H_{b}, H_{0} / H_{b}$ and $H_{b} / h_{b}$ values on prototype scale. Figure 10 shows the corresponding values of the breaker height $\left(H_{b}\right)$, the offshore wave height divided by the breaker height $\left(H_{0} / H_{b}\right)$ and the breaker parameter $H_{b} / h_{b}$. From these two figures it can be seen that all breaker heights $H_{b}$ and all relations $H_{0} / H_{b}$ are almost the same. The breaking point is, as in the physical experiments (Voorde 2009), more seawards in case of the lower reef.

It was expected that the higher the reef the higher the parameter $H_{b} / h_{b}$ would be, as this value is higher for a relatively large slope than for a relatively small one (Komar 1998), and the large slope is experienced for longer when the height of the reef is larger.

Figure 10 shows that $H_{b} / h_{b}$ is significantly larger for the $3.20 \mathrm{~m}$ reef than for the one $1.90 \mathrm{~m}$ high. The value for the $3.90 \mathrm{~m}$ reef is again somewhat smaller, but not much.

The slope of the reef

The slope of the reef, s_reef, is the second parameter that will be investigated, because the submergence of the reef is restricted to certain values for safety reasons. The geometry and the wave conditions are shown in Fig. 11 and Table 4. Figures 12, 13, 14, and 15 show the shape of the breaking wave for these four cases.

Figure 12 shows that a breaker shape close to surging is formed with a slope of 1:6. Figures 13 and 14 show that a plunging surfable wave is formed with slopes of 1:10 and 1:14. Figure 15 shows that a spilling break is formed which tries to break like plunging one at first but is not able to. From the results presented in Figures 12, 13, 14, and 15 it can be concluded that the wave really should experience a slope between 1:10 and 1:14.

Figure 16 shows the wave height at several points on the reef for all four tested slopes. Figure 17 shows the corresponding values of the breaker height $\left(H_{b}\right)$, the 
Fig. 18 Submergence of the reef: tested geometry

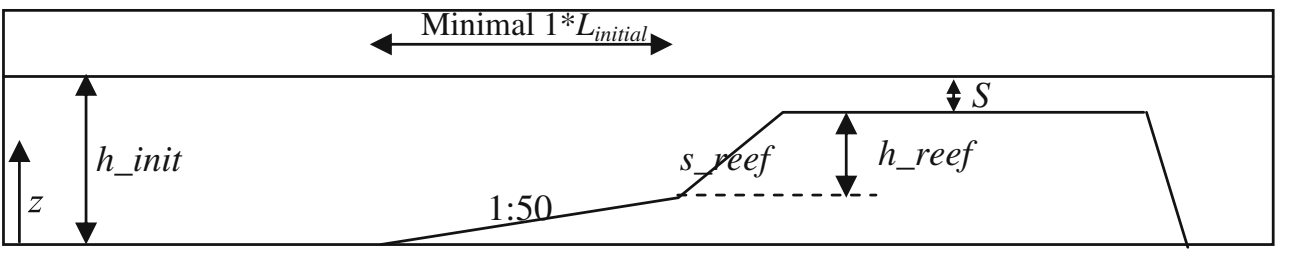

offshore wave height divided by the breaker height $\left(H_{0} / H_{b}\right)$ and the breaker parameter $H_{b} / h_{b}$. From these two figures it can be seen that all breaker heights $H_{b}$ and all relation values of $H_{0} / H_{b}$ are almost the same. However, the breaking point shifts away from the top of the reef the larger the slope gets. The breaker parameter $H_{b} / h_{b}$ decreases when the slope of the reef gets smaller. So these data confirm the results of Komar (1998) that the factor $H_{b} /$ $h_{b}$ grows when the slope gets relatively larger.

The submergence of the reef

The submergence of the reef, $S$, is the third parameter that is investigated. Contrary to the previous two cases, the initial height, $h$ _init, varies in these simulations. The geometry and the wave conditions are shown in Fig. 18 and Table 5. Figures 19, 20, 21, and 22 show the shape of the breaking wave for these four cases. Figure 20 can be compared with Fig. 3a, since it shows a sequence of numerical results for the same experimental conditions of the latter figure, unless the height of the reef, which is $3.20 \mathrm{~m}$ (prototype scale) instead of $3.60 \mathrm{~m}$.

The wave shape with a submergence of $1.50 \mathrm{~m}$ still seems very good; so for both the wave shape and safety considerations a submergence equal to the design wave height is chosen. Figure 23 shows the wave height at several points on the reef for all four tested submergences. Figure 24 shows the values of the breaker height $\left(H_{b}\right)$, the initial wave height divided by the breaker height $\left(H_{0} / H_{b}\right)$ and the breaker parameter $H_{b} / h_{b}$.

Figure 23 shows clearly that the breaking point shifts more towards the end of the shore as the submergence gets smaller, which is exactly as expected. Figure 24 shows that the factor $H_{b} / h_{b}$ is almost the same for all tested submergences.

Table 5 Submergence of the reef: geometry parameters and wave conditions

\begin{tabular}{lcllll}
\hline$S(\mathrm{~m})$ & h_init $(\mathrm{m})$ & h_reef $(\mathrm{m})$ & s_reef & $H(\mathrm{~m})$ & $T(\mathrm{~s})$ \\
\hline 0.80 & 6.80 & 3.20 & $1: 10$ & 1.50 & 9.0 \\
1.20 & 7.20 & & & & \\
1.50 & 7.50 & & & & \\
2.0 & 8.00 & & & & \\
\hline
\end{tabular}

\section{Results and discussion}

There are several reasons why it would be unrealistic to present a single optimal MFAR design for all parts of the world. These reasons have to do with local circumstances like tidal range, wave climate, bathymetry, currents and sediment transport, and the budget.

However, several design parameters have to be considered for the design of any artificial reef that is to be built to both protect the local coastline and to create surfing conditions. Some of physical and numerical research undertaken concerned the factors that should be taken into account in terms of hydrodynamics for the parameters with most influence in the vertical plane.

The main findings or confirmations of this research work can be summarized as follows.

A Influence of the height of the reef:

- A reef length of about $0.5 \times L_{\text {start reef }}$ is the minimum required to form a surfable wave, being $L_{\text {start_reef }}$ the wave length at the start of the reef.

- The higher the reef the higher the breaker parameter $H_{b} / h_{b}$ and more seawards the wave breaks.

$\mathrm{B}$ Influence of the slope of the reef:

- Within a convenient interval, restricted to values of about $[1: 8,1: 16]$ for safety reasons, the larger the
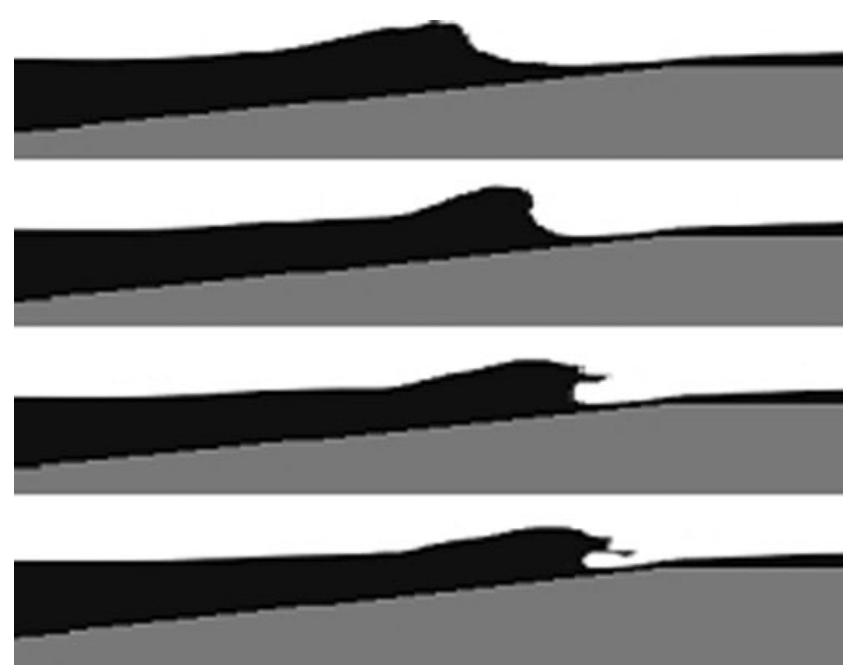

Fig. 19 Wave shape on the reef with a submergence of $0.80 \mathrm{~m}$ (h_init= $6.80 \mathrm{~m}$, h_reef $=3.20 \mathrm{~m}, H=1.50 \mathrm{~m}, T=9.0 \mathrm{~s}$ ) 

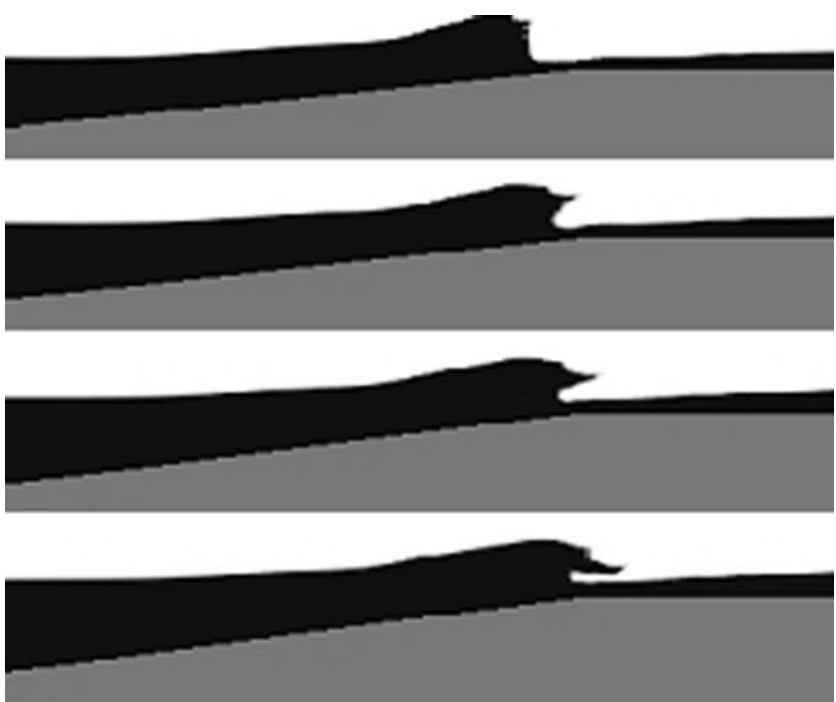

Fig. 20 Wave shape on the reef with a submergence of $1.20 \mathrm{~m}$ (h_ init= $7.20 \mathrm{~m}, \mathrm{~h} \_$reef $=3.20 \mathrm{~m}, H=1.50 \mathrm{~m}, T=9.0 \mathrm{~s}$ )

slope of the reef the higher the breaker parameter $H_{b} / h_{b}$.

- For slopes between 1:10 and 1:14, the wave really should experience a slope and breaks accordingly to it.

- The breaking position shifts away from the top of the reef the larger the slope gets.

$\mathrm{C}$ Influence of the submergence of the reef:

- The breaking point shifts more towards the end of the shore as the submergence gets smaller.

- For both the wave shape and safety considerations, submergence equal to the design wave height is chosen.
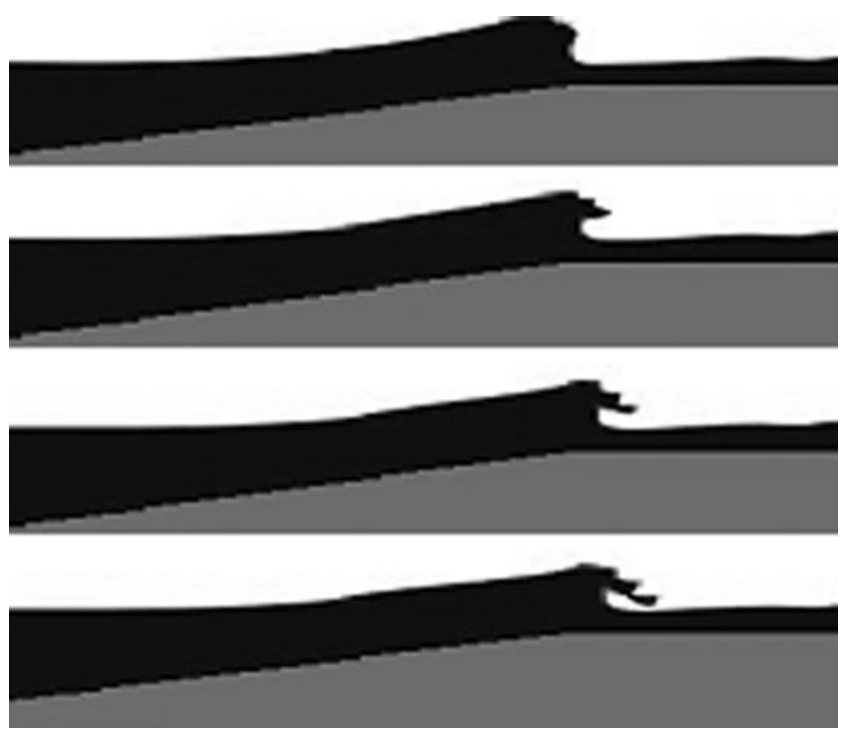

Fig. 21 Wave shape on the reef with a submergence of $1.50 \mathrm{~m}$ (h_init= $7.50 \mathrm{~m}$, h_reef $=3.20 \mathrm{~m}, H=1.50 \mathrm{~m}, T=9.0 \mathrm{~s}$ )
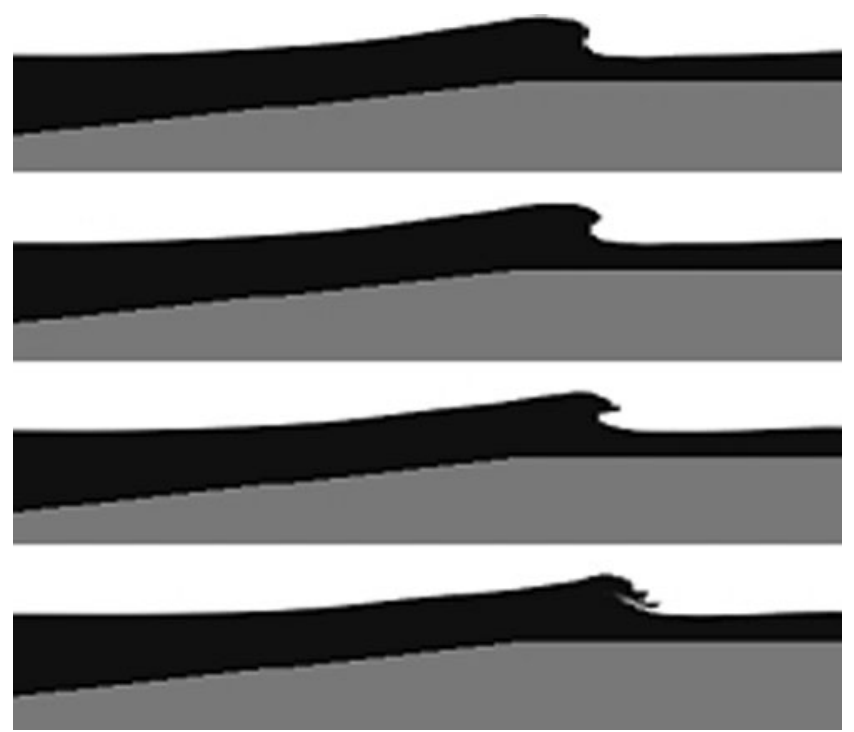

Fig. 22 Wave shape on the reef with a submergence of $2.0 \mathrm{~m}$ (h_init= $8.00 \mathrm{~m}, \mathrm{~h} \_$reef $=3.20 \mathrm{~m}, H=1.50 \mathrm{~m}, T=9.0 \mathrm{~s}$ )

From the numerical tests it can be concluded that, for the design wave height of $1.50 \mathrm{~m}$, good surfing wave will be obtained for a submergence equal to the design wave height $(1.50 \mathrm{~m})$ and for a reef height of $3.20 \mathrm{~m}$ and a seaward slope of 1:10.

Some research questions were raised during this investigation, which lead to the following recommendations for future work:

- The investigation of the wave shape, both in the laboratory and in the numerical studies, was carried out on a submerged reef with a smooth slope and a rigid material bottom. However, it would be useful to investigate the wave shape over porous bottoms like geotextile sand containers, as this is the material which is the most suitable for building an MFAR. The turbulence and the energy dissipation will be different in these containers from what they are over a rigid bottom, and this is expected to have an influence on the wave shape.

- A 3D version of the COBRAS-UC is in development, and it would be useful to use it or a similar numerical model to simulate the wave shape on and around an MFAR.

- In terms of coastal protection, other physical and numerical hydrodynamic and morphodynamic studies must be conducted in order to analyze the influences of other important reef parameters in the 2DH plane, like the reef angle, the horizontal dimensions of the reef, the use of a delta structure with or without a platform, and the presence or absence of significant ambient longshore sediment transport. 
Fig. 23 Submergence of the reef: wave height development on the reef

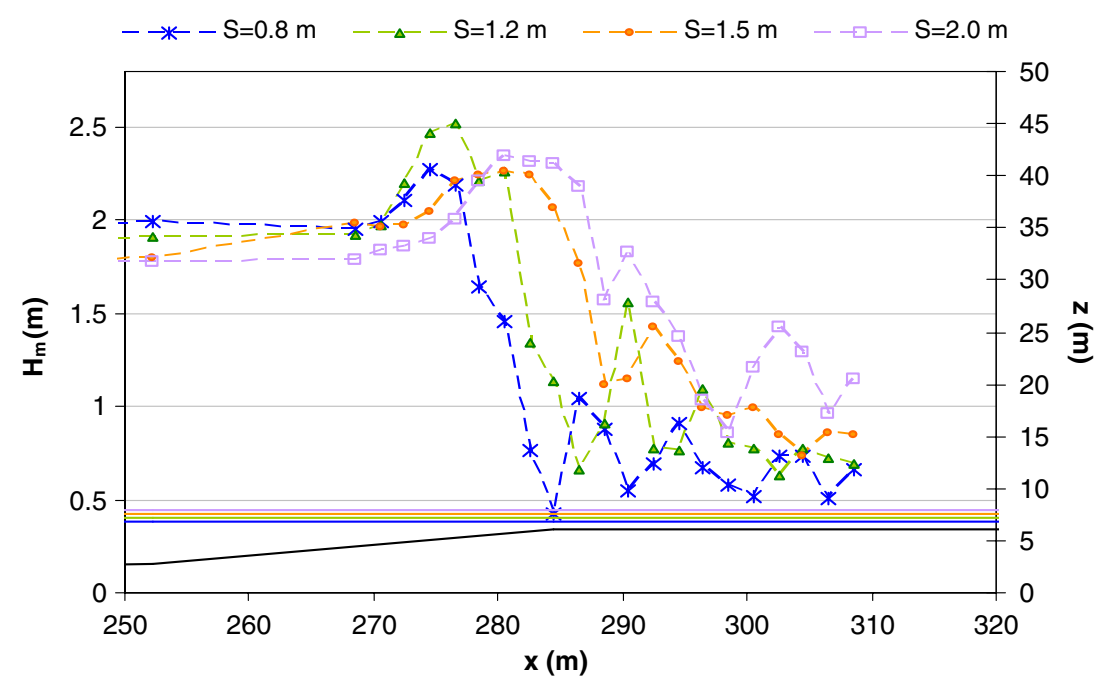

\section{Conclusion}

This paper describes the numerical studies conducted with the COBRAS-UC model in the vertical plane, which were meant to gain insight into the breaker type and into the position of the breaking wave for several heights, submergences and slopes of the reef, on prototype scales.

For the Leirosa case study, initial values of several parameters were determined from the numerical tests conducted in the 2DV plane, supported on physical data obtained at the LNEC flume. The following values were obtained: the height of the reef is $3.20 \mathrm{~m}$, the seaward slope of the reef is $1: 10$, the reef submergence is equal to the design wave height of $1.50 \mathrm{~m}$, and the length of the reef should be at least half the wave length at the start of the reef, so equal to or greater than $30 \mathrm{~m}$ in this case.

The position of the reef should be such that the distance from the apex of the structure to the undisturbed shoreline is greater than 1.5 the natural surf zone width (Voorde 2009).

Keeping the two main functions of an MFAR in mind, coastal protection and increasing the surfing possibilities in a certain area, it must be emphasized that once an optimal

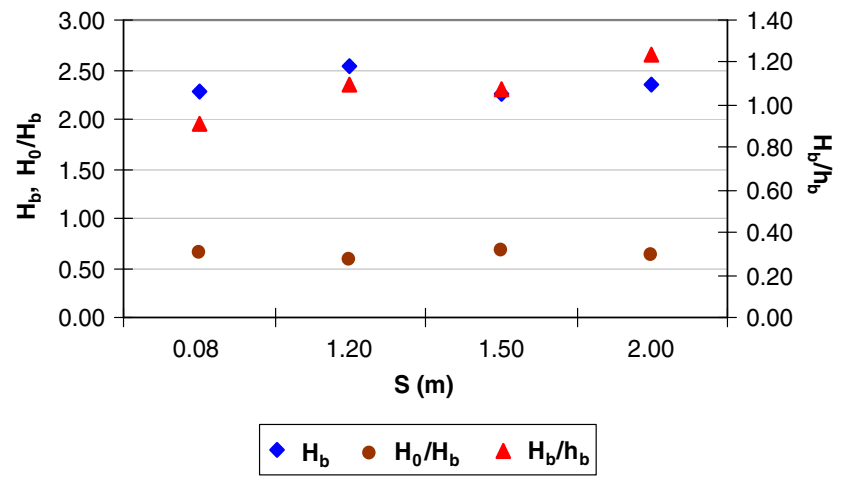

Fig. 24 Influence of $S$ on the values of $H_{b}, H_{0} / H_{b}$ and $H_{b} / h_{b}$ geometry has been determined in relation to hydrodynamics, a thorough morphodynamic study (physical and/or numerical) is needed to investigate the ability of the MFAR to protect the local coastline.

Acknowledgements The authors gratefully acknowledge the Fundação para a Ciência e a Tecnologia under the project PTDC/ECM/66516/2006 and the financial sponsorship of M. ten Voorde's Ph.D. research by the Instituto de Investigação Interdisciplinar, Coimbra, Portugal. The authors also gratefully acknowledge to the University of Cantabria the permission to use the COBRAS-UC model.

\section{References}

Edwards R (2003) A brief description of the Biological Assemblages Associated with Narrowneck Artificial Reef and Non-Woven Geotextile Substratum. Prepared for Soil Filters Australia

Garcia N, Lara JL, Losada IJ (2004) 2-D Numerical analysis of nearfield flow at low-crested permeable breakwaters. Coastal Eng 51:991-1020

Henriquez M (2004) Artificial surf reefs. MSc thesis, Delft University of Technology (www.waterbouw.tudelft.nl)

Hsu T-J, Sakakiyama T, Liu PL-F (2002) A numerical model for wave motions and turbulence flows in front of a composite breakwater. Coastal Eng 46:25-50

Jackson LA, Reichelt RE, Restall S, Corbett B, Tomlinson R, McGrath J (2004) Marine ecosystem enhancement on a geotextile coastal protection reef-Narrowneck reef case study, 29th International Conference on Coastal Engineering, Lisbon, Portugal, 3940-3952

Kaminsky GM, Kraus NC (1993) Evaluation of depth-limited wave breaking criteria. Proceedings of $2^{\text {nd }}$ International Symposium on Ocean Wave Measurements and Analysis, Waves'93, Amer Soc Civil Engrs, New York, 180-193

Komar PD (1998) Beach processes and sedimentation, 2nd edn. Prentice Hall, New Jersey

Lara JL, Garcia N, Losada IJ (2006a) RANS modelling applied to random wave interaction with submerged permeable structures. Coastal Eng 53:395-417

Lara JL, Losada IJ, Liu PL-F (2006b) Breaking waves over a mild gravel slope: experimental and numerical analysis. J Geophys Res AGU 111:C11019 
Lara JL, Losada IJ, Guanche R (2008) Wave interaction with lowmound breakwaters using a RANS model. Ocean Eng 35:13881400

Lin P, Liu PL-F (1998) A numerical study of breaking waves in the surf zone. J Fluid Mech 359:239-264

Liu PL-F, Lin P, Chang KA, Sakakiyama T (1999) Numerical modeling of wave interaction with porous structures. J Waterw Port Coast Ocean Eng 125:322-330

Losada IJ, Lara JL, Damgaard E, Garcia N (2005) Modelling of velocity and turbulence fields around and within low-crested rubble-mound breakwaters. Coastal Eng 52:887-913

Losada IJ, Lara JL, Guanche R, Gonzalez-Ondina JM (2008) Numerical analysis of wave overtopping of rubble mound breakwaters. Coastal Eng 55(1):47-62

Pilarczyk KW (2003) Design of low-crested (submerged) structuresan overview, 6th International Conference on Coastal and Port Engineering in Developing Countries, Colombo, Sri Lanka

Ranasinghe R, Turner IL, Symonds G (2006) Shoreline response to multifunctional artificial surfing reefs: a numerical and physical modelling study. Coastal Eng 53:589-611
Rodi W (1980) Turbulence models and their application in hydraulics - a state of the art review. I.A.H.R. Publication, Delft

Voorde MT (2009) Contribution to the design of Multifunctional Artificial Reefs. PhD thesis, University of Coimbra, Coimbra, Portugal

Voorde MT, Antunes do Carmo JS, Neves MG (2008) Numerical investigation of multifunctional artificial reefs for coastal protection, 1st PoCoast seminar on Coastal Research, Porto, Portugal (in press)

Voorde MT, Antunes do Carmo JS, Neves MG (2009a) Multifunctional artificial reefs for coastal protection. In: Hudspeth ChA, Reeve TE (eds) Agricultural runoff, coastal engineering and flooding. Nova Science Publishers, Inc, USA, ISBN: 978-160741-097-3, pp 153-210

Voorde MT, Antunes do Carmo JS, Neves MG (2009b) Designing a preliminary multifunctional artificial reef to protect the Portuguese coast. J Coast Res 25(1):69-79

Voorde MT, Antunes do Carmo JS, Neves MG (2009c) Physical and numerical study of 'breaker types' over an artificial reef. J Coast Res SI56:569-573 